\title{
LEHRBUCH
}

DER

\section{PRAKTISCHEN THEOLOGIE}

VON

\section{E. CHR. ACHFLIS}

PROFESBOR DER THEOLOGIE GEH. KONSISTORIALRAT IN MARBURG

DRITTE TEILWEISE NEUBEARBEITETE AUFLAGE

\section{ERSTER BAND}

EINLEITUNG - DIE LEHRE VON DER KIRCHE UND IHREN ÄMTERN -

DIE LEHRE VOM KULTUS (1. BUCH: LITURGIK)

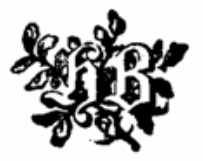

LEIPZIG

J. C. HINRICHS'SCHE BUCHHANDLUNG 
Alle Rechte, insbesondere das der Übersetzung, vorbehalten. 